\title{
The Whys of \\ Subnuclear Physics
}




\section{THE SUBNUCLEAR SERIES}

Series Editor: ANTONINO ZICHICHI

European Physical Society

Geneva, Switzerland

1. 1963 STRONG, ELECTROMAGNETIC, AND WEAK INTE RACTIONS

2. 1964 SYMMETRIES IN ELEMENTARY PARTICLE PHYSICS

3. 1965 RECENT DEVELOPMENTS IN PARTICLE SYMMETRIES

4. 1966 STRONG AND WEAK INTERACTIONS

5. 1967 HADRONS AND THEIR INTERACTIONS

6. 1968 THEORY AND PHENOMENOLOGY IN PARTICLE PHYSICS

7. 1969 SUBNUCLEAR PHENOMENA

8. 1970 ELEMENTARY PROCESSES AT HIGH ENERGY

9. 1971 PROPERTIES OF THE FUNDAMENTAL INTE RACTIONS

10. 1972 HIGHLIGHTS IN PARTICLE PHYSICS

11. 1973 LAWS OF HADRONIC MATTER

12. 1974 LEPTON AND HADRON STRUCTURE

13. 1975 NEW PHENOMENA IN SUBNUCLEAR PHYSICS

14. 1976 UNDERSTANDING THE FUNDAMENTAL CONSTITUENTS OF MATTER

15. 1977 THE WHYS OF SUBNUCLEAR PHYSICS

Volume 1 was published by W. A. Benjamin, Inc., New York; 2-8 and 11-12 by Academic Press, New York and London; 9-10 by Editrice Compositori, Bologna; 13-15 by Plenum Press, New York and London. 


\title{
The Whys of \\ Subnuclear Physics
}

\author{
Edited by \\ Antonino Zichichi
}

European Physical Society

Geneva, Switzerland

PLENUM PRESS • NEW YORK AND LONDON 


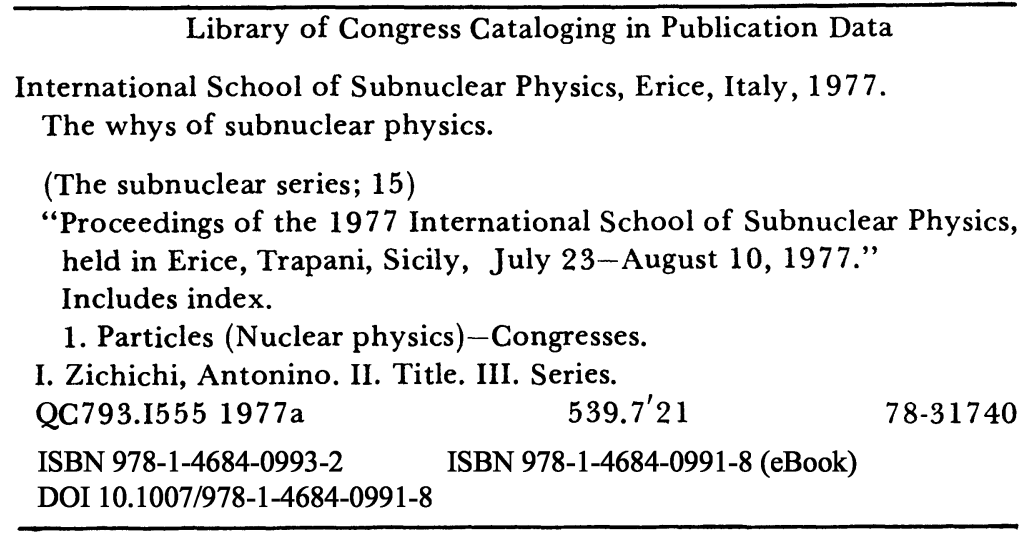

Proceedings of the 1977 International School of Subnuclear Physics held in Erice, Trapani, Sicily, July 23-August 10, 1977

(c) 1979 Plenum Press, New York

Softcover reprint of the hardcover 1 st edition 1979

A Division of Plenum Publishing Corporation 227 West 17 th Street, New York, N.Y. 10011

All rights reserved

No part of this book may be reproduced, stored in a retrieval system, or transmitted, in any form or by any means, electronic, mechanical, photocopying, microfilming, recording, or otherwise, without written permission from the Publisher 


\section{Preface}

From 23 Ju1y to 10 August 1977 a group of 125 physicists from 72 laboratories of 20 countries met in Erice to attend the 15 th Course of the International School of Subnuclear Physics.

The countries represented at the School were: Belgium, Bulgaria, Denmark, Federal Republic of Germany, Finland, France, Hungary, Ireland, Israel, Italy, Japan, the Netherlands, Norway, Poland, Sweden, Switzerland, the United Kingdom, the United States of America and Venezuela.

The School was sponsored by the Italian Ministry of Public Education (MPI), the Italian Ministry of Scientific and Technological Research (MRST), the North Atlantic Treaty Organization (NATO), the Regional Sicilian Government (ERS) and the Weizmann Institute of Science.

The School was very exciting due to the impressive number of frontier problems which were discussed. Being the 15 th year of the School, it was decided to review all outstanding "Whys".

At various stages of my work I have enjoyed the collaboration of many friends whose contributions have been extremely important for the School and are highly appreciated. I would like to thank Dr. A. Gabriele, Ms. S. McGarry, Mr. and Mrs. S. Newman, Ms. P. Savalli and Ms. M. Zaini for the general scientific and administrative work.

Finally, I would like to thank most warmly all those in Erice, Bologna and Geneva who helped me on so many occasions and to whom I feel very much indebted.

A. Zichichi

Geneva, September 1978 


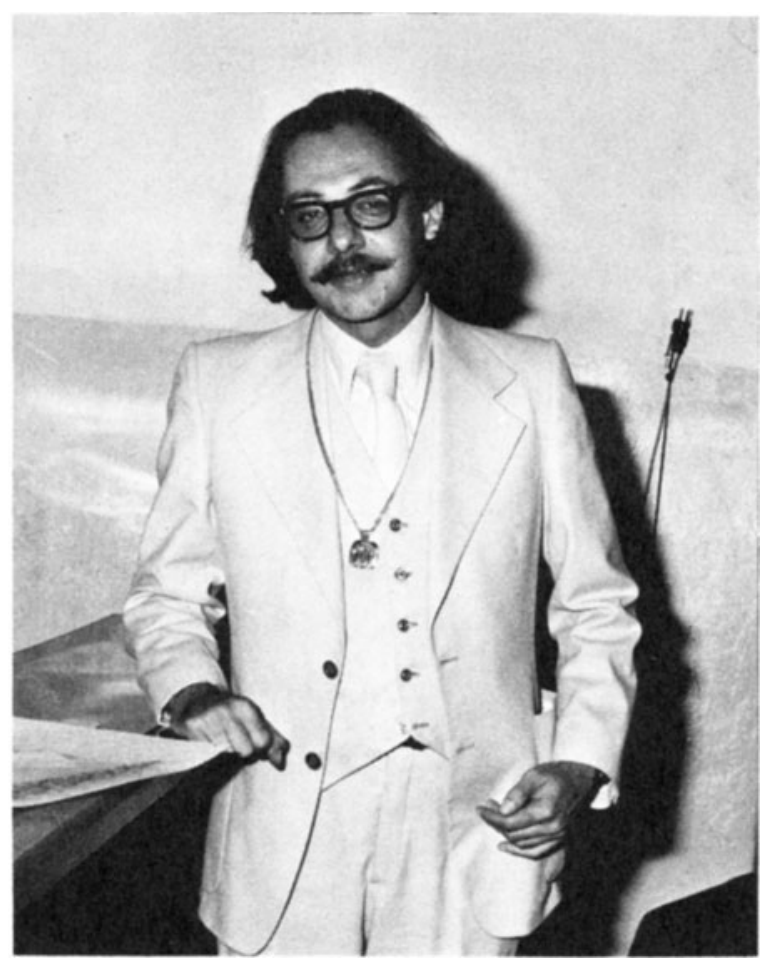

Professor Sidney Coleman has been awarded the Prize of

"Best Lecturer"

on the occasion of the 15th anniversary of the International School of Subnuclear Physics. 


\section{Contents}

The Whys of Subnuclear Physics $\ldots \ldots \ldots \ldots \ldots \ldots \ldots \ldots \ldots \ldots \ldots$

$$
\text { A. Zichichi }
$$

Why Is There Charm, Strangeness, Colour and All That?

H. J. Lipkin

Do Mesons Fill SU(3) Nonets?

R. Bizzarri

The Properties of Charmonium and Charm

$$
\text { Particles }
$$

H. Schopper

Recent Results from DASP

B. H. Wiik

New Particles or "Why I Believe in Quarks"

A. Martin

New Particle Production in Hadronic Interactions

M. Chen

Review of Lepton Production in Hadron - Hadron

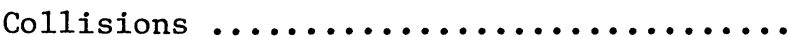

A. J. S. Smith

Narrow Resonances in $\overline{\mathrm{B} B}$ Reactions

S. Nilsson

Parton Distributions and Their $\mathrm{Q}^{2}$ Dependence N. Cabibbo

Total Cross Sections of Neutrinos and Antineutrinos in $\mathrm{BEBC}$ in

the Energy Range $20-200 \mathrm{GeV}$

P. Renton 
Measurement of Neutral Current CrossSections and Their Energy

H. P. Paar

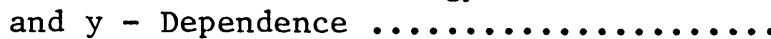

Charged V+A Currents in Left-Right Symmetric R. Burny

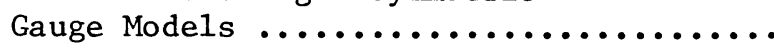

Quark and Lepton Mixing N. Cabibbo

Quark-Geometrodynamics: A New Approach to

Hadrons and Their Interactions

G. Preparata

The Uses of Instantons

S. Coleman

Can We Make Sense Out of "Quantum Chromodynamics"?

G. 't Hooft

Should We Believe in Quantum Field Theory? ............

A. S. Wightman

An Exact Relativistic S-Matrix in 1+1 Dimensions:

The On-Shell Solution of the

Massive Thirring Model and the

Quantum Sine-Gordon Equation ..........

M. Karowski

Dynamical Symmetries in Nuclear Physics .............. 1043

F. Iachello

Symmetries of Quarks and Leptons $\ldots \ldots \ldots \ldots \ldots \ldots \ldots$

F. Gürsey

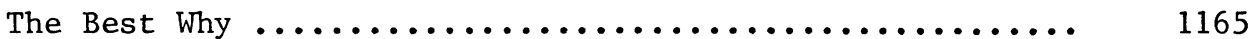

A. Sanda

Status of the Subnuclear Whys $\ldots \ldots \ldots \ldots \ldots \ldots \ldots \ldots$

A. Zichichi

List of Prizes Awarded, Scholarships, etc. .......... 1215

List of Participants ...................... 1217

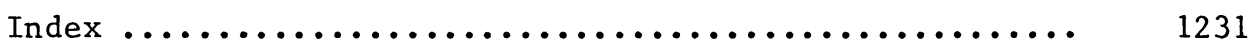

